\title{
Cushing Syndrome due to Ectopic ACTH Secretion Presenting With Lower Limb Edema and Pulmonary Nocardia Infection: Case Report and Review of the Literature
}

\author{
Marylene Samia El Hayek ${ }^{\mathrm{a}}$, Mahmoud Choucair ${ }^{\mathrm{a}}$, Asma Arabi $^{\mathrm{a}}$ b
}

\begin{abstract}
Ectopic ACTH secretion has been described since 1962, but its presentation as only lower limbs edema was rarely described. Symptoms and signs are very similar to Cushing disease, but with a more rapid onset and progression of symptoms. Cushing syndrome presenting as lower limbs edema only has been reported once. We present here a case of a 60-year-old male patient with ectopic ACTH secretion presenting with isolated lower limb edema and developing pulmonary nocardia infection.
\end{abstract}

Keywords: Ectopic ACTH; Cushing; Nocardia; Limb edema

\section{Introduction}

Excess glucocorticoids secretion was first described by Harvey Cushing in 1912. Twenty years later, he postulated that it was due to a primary pituitary abnormality causing adrenal hyperplasia, but it was until 1962 that ectopic secretion of ACTH was characterized. Ectopic ACTH secretion is responsible for $20 \%$ of ACTH-dependent Cushing syndrome [1]. Differentiating between ectopic ACTH secretion and Cushing disease remains a challenging problem [1]. Despite detailed investigation, the cause of corticotropin production might remain occult in $5-15 \%$ of patients, and these patients need continued followup $[2,3]$. Several clinical pictures of glucocorticoid excess have been described. Symptoms and signs are very similar to Cushing disease; however, the rapidity of onset and progression of symptoms are more suggestive of an ectopic ACTH secretion. Most frequently reported are muscle weakness, increased body weight, hypertension, menstrual irregularities

Manuscript accepted for publication August 22, 2016

${ }^{a}$ Department of Internal Medicine, Division of Endocrinology and Metabolism, American University of Beirut, Beirut, Lebanon

${ }^{\mathrm{b}}$ Corresponding Author: Asma Arabi, Department of Internal Medicine, Division of Endocrinology and Metabolism, American University of Beirut, PO Box 11-0236, Riad El-Solh, Beirut 1107 2020, Lebanon.

Email: aa22@aub.edu.lb

doi: http://dx.doi.org/10.14740/jem372w and hirsutism in women, osteoporosis and hypokalemia with a frequency ranging between $70 \%$ and $80 \%$. About half of the patients will complain of diabetes, infections and violaceous striae [4]. However, Cushing syndrome presenting as lower limbs edema only has been reported once [5].

\section{Case Report}

A 60-year-old Iraqi man presented to our tertiary care center in Beirut for evaluation of bilateral lower limbs edema of 2 months duration. Relevant past medical history was positive for type 2 diabetes mellitus (DM2) of 13 years duration, with peripheral diabetic neuropathy and nephropathy, hypertension, and dyslipidemia. His home medications included premixed insulin (neutral protamine Hagedorn with regular insulin), rosuvastatin, nebivolol, valsartan, and hydrochlorothiazide and he was recently started on bumetanide $1 \mathrm{mg}$ daily. The patient was clinically euthyroid. On physical exam, he had bilateral lower limbs pitting edema, extending to the knees. His blood pressure was 120/70 mm Hg, he had regular heart sounds and clear lungs and there was no jugular venous distension. No Cushingoid facies, no skin striae or ecchymoses were noted.

Preliminary laboratory workup showed proteinuria of 2.3 $\mathrm{g} / 24 \mathrm{~h}$ with normal creatinine of $0.5 \mathrm{mg} / \mathrm{dL}(0.6-1.2 \mathrm{mg} / \mathrm{dL})$, normal sodium $145 \mathrm{mmol} / \mathrm{L}(135-145 \mathrm{mmol} / \mathrm{L})$, hypokalemia of $3.1 \mathrm{mmol} / \mathrm{L}(3.5-5.1 \mathrm{mmol} / \mathrm{L})$ with metabolic alkalosis, bicarbonate of $40 \mathrm{mmol} / \mathrm{L}(24-30 \mathrm{mmol} / \mathrm{L})$, low normal albumin level $35 \mathrm{~g} / \mathrm{L}(36-53 \mathrm{~g} / \mathrm{L})$ and normocytic anemia with a hemoglobin of $11.4 \mathrm{~g} / \mathrm{dL}(13-18 \mathrm{~g} / \mathrm{dL})$, white blood count of $10,800 / \mathrm{mm}^{3}\left(4,000-11,000 / \mathrm{mm}^{3}\right)$ (neutrophils: $85 \%$ ), and platelets count of $108,000 / \mathrm{mm}^{3}\left(150,000-400,000 / \mathrm{mm}^{3}\right)$. Echocardiography found an ejection fraction of $50-59 \%$ with grade 1 diastolic dysfunction. Thyroid function tests showed TSH was $0.44(0.27-4.2 \mu \mathrm{U} / \mathrm{mL})$, low FT3 was $0.65 \mathrm{pg} / \mathrm{mL}$ $(1.8-4.6 \mathrm{pg} / \mathrm{mL})$ and FT4 was $0.78 \mathrm{ng} / \mathrm{dL}(0.93-1.7 \mathrm{ng} / \mathrm{dL})$. Ultrasound of the kidneys was normal. Doppler ultrasound of lower extremities did not show evidence of deep venous thrombosis. The hypokalemia was initially attributed to bumetanide use but it persisted and even after discontinuation of the diuretic $(2.4 \mathrm{mmol} / \mathrm{L})$. Additional tests were then requested, including a complete pituitary function that revealed normal prolactin level, hypogonadism with testosterone of $95.6 \mathrm{ng} / \mathrm{dL}$ (249 
- $836 \mathrm{ng} / \mathrm{dL}$ ) and low LH of $2.5 \mathrm{mIU} / \mathrm{mL}$ (5 - $12 \mathrm{mIU} / \mathrm{mL})$, elevated ACTH of $312 \mathrm{pg} / \mathrm{mL}(10-60 \mathrm{pg} / \mathrm{mL})$ and high morning cortisol level of $40.7 \mu \mathrm{g} / \mathrm{dL}$ ( $4-25 \mu \mathrm{g} / \mathrm{dL})$. An overnight low dose dexamethasone suppression test did not suppress morning cortisol (cortisol level $36 \mu \mathrm{g} / \mathrm{dL}$ ). High dose $8 \mathrm{mg}$ overnight dexamethasone test failed to suppress cortisol level as well: $28 \mu \mathrm{g} / \mathrm{dL}$. MRI of the sella was performed and was normal. Chest X-ray showed a prominent right hilum. CT chest showed multilobar consolidations likely pneumonic with left apical and right lower lobe lung masses. Spondylotic changes with multiple compression fractures and paraspinal abscess at T12 level were also noted. Blood cultures and culture from abscess grew Salmonella typhi. Bronchoscopy was normal and bronchoalveolar lavage was negative for malignancy, but grew Nocardia species. The patient was discharged home on double antibiotics coverage (trimetoprim-sulfametoxazole and meropenem). Waiting for resolution of the bacteremia to do further investigations, the patient was started on ketoconazole $200 \mathrm{mg}$ BID, increased to TID. As his repeated cortisol was still high after 1 week of a daily dose of $600 \mathrm{mg} /$ day, mitotane $500 \mathrm{mg}$ TID was added. He was planned to do PET scan, and if negative, bilateral inferior petrosal sinus sampling (BIPSS) after resolution of the bacteremia, but he went back to Iraq and was lost of follow-up since then.

\section{Discussion}

We presented a case of ectopic ACTH secretion in a 60-yearold patient presenting with hypokalemia, lower limb edema and multilobar consolidations with left apical and right lower lobe lung masses with normal bronchoscopy and a bronchoalveolar lavage that was negative for malignancy, but grew Nocardia species. To our knowledge, ectopic ACTH secretion presenting as isolated lower lib edema was reported only once, and cases reporting association with Nocardia infection are scarce.

\section{Hypercortisolemia and infection}

The increased susceptibility to infections was noted since Cushing's original description of the disease, with a predisposition to opportunistic infections. The risk of infection is influenced by the underlying cause of hypercortisolemia, and seems to be correlated with higher general levels of ambient steroid. This risk is highest with exogenous steroids, followed by ectopic ACTH secretion, then other causes of endogenous hypercortisolism [6, 7].

Deficits in cell-mediated immunity as well as alterations in neutrophils and macrophages functions predispose patients with Cushing syndrome to fungal infections. For example, Candida infections can be superficial, or it can cause bloodstream infections with septicemia. Aspergillus causes most of the invasive fungal infections in patients treated with glucocorticoids. Pneumocystis jiroveci is well known to cause pneumonia in patients treated with glucocorticoids [8].

Elevated cortisol levels predispose patients to more se- vere, disseminated and prolonged viral infections, including, as examples, infections with herpes simplex viruses, varicella zoster, and cytomegalovirus. Both Gram-positive bacteria such as Staphylococci, streptococci and listeria, and Gram-negative organisms including enterobacteriacae and Legionella are seen in increased frequency in patients with hypercortisolemia [8].

Nocardia asteroides, an uncommon filamentous Grampositive organism, has been previously reported in few cases of hypercortisolemia.

Rizwan et al described three cases of ectopic Cushing syndrome presenting with uncontrolled hypertension, elevated blood sugar and hypokalemia. CT chest of these subjects demonstrated cavitatory lung lesions. Microscopic analysis of respiratory samples was suggestive of infection with Nocardia species; however, histopathology of bronchoscopic-guided biopsy revealed no malignancy. Antihypertensives, insulin, potassium replacement, ketoconazole and trimethoprim-sulphamethoxazole were initiated. The patients' symptomatology improved and cavitatory lesions resolved with treatment; however, the primary source for the ectopic Cushing remained unknown [9].

Dohchin et al reported a 54-year-old male patient who presented for further investigation of multiple nodules disclosed by a chest roentgenogram. Investigations revealed an occult ectopic ACTH syndrome. Bronchial secretion samples obtained by bronchoscopy contained Nocardia asteroides bacteria. After treatment with sulfamethoxazole-trimethoprim, the nodules gradually disappeared, leaving only scars. However, pulmonary nocardiosis relapsed following the termination of sulfamethoxazole-trimethoprim therapy despite mitotane therapy to suppress hypercortisolemia [10].

Huang et al reported a 25-year-old man diagnosed with ectopic Cushing syndrome due to an ACTH producing small cell lung carcinoma who had a rapidly progressive course of pulmonary nocardiosis and died 3 days after the initiation of antibiotics and ketoconazole [11].

Sutton et al presented the case of a 42-year-old woman who had Cushing syndrome due to a carcinoid tumor in the lung secreting ACTH. Her course was complicated by the appearance of multiple pulmonary nodules, which were shown by fine needle aspiration to be infectious in nature. A Gram stain revealed numerous Gram-positive branching organisms, and culture of the specimen grew Nocardia asteroides. Her pulmonary infection was treated with antibiotics and she underwent successful ablation of the carcinoid tumor [12].

\section{Hypercortisolemia and lower limbs edema}

Few cases have reported the presentation of Cushing syndrome as only lower limbs edema. Of note, Lin et al described a 43-year-old patient presenting for bilateral lower limbs edema, hyperpigmentation and easy bruisability who was found to have ectopic Cushing syndrome due to a small cell lung cancer. His endocrinologic workup was relevant for hypogonadism and hypothyroidism [5].

This is the second case reported to describe the presentation of hypercortisolemia as lower extremities edema. It is noted that our patient had also central hypogonadism and labo- 
ratory findings suggestive of central hypothyroidism.

\section{Hypercortisolemia and hypokalemia}

ACTH level in our patient at presentation was $312 \mathrm{pg} / \mathrm{mL}$. Plasma ACTH levels tend to be higher in the ectopic ACTH syndrome (EAS) than in Cushing's disease, but there is a large overlap between values and no cut-off limit was found for the definite and clear distinction. ACTH levels were elevated more than $200 \mathrm{ng} / \mathrm{L}$ in $50-64 \%$ of subjects with ectopic ACTH secretion. No correlation could be established with the tumor size, as ACTH levels did not differ in patients with occult and overt ectopic ACTH syndrome [13-16].

Hypokalemic alkalosis is found in $10-15 \%$ of patients with Cushing's disease, but in more than $95 \%$ of patients with ectopic ACTH syndrome. High concentrations of cortisol can either saturate the 11ß-hydroxysteroid dehydrogenase type II enzyme in the kidney or decrease its expression, allowing cortisol to act even more as a mineralocorticoid causing potassium losses. Hypokalemia reflects the prevailing levels of cortisol rather than the specific etiology. It has a high sensitivity for the ectopic ACTH syndrome, but a specificity that only approaches the pretest likelihood $[17,18]$.

\section{Conclusion}

Ectopic ACTH secretion that is complicated by severe Cushing syndrome is often a devastating disease. It is associated with many opportunistic infections notably with Nocardia species. Its presentation as bilateral lower extremities edema has been rarely reported. Aggressive therapy for hypercortisolemia should be instituted. If ipatients cannot undergo curative or palliative surgery, medical therapy should be applied with mifepristone or combination therapy with inhibitors of steroidogenesis according to individual patient characteristics. In selected cases, somatostatin analogs may be effective [19].

\section{Conflicts of Interest}

The authors have no conflicts of interest to declare.

\section{References}

1. Stewart PM, Krone NP. The adrenal cortex. In: Williams Textbook of Endocrinology, Twelfth edition, Chapter 15, 2011: 479-544.

2. Orlefors H, Sundin A, Garske U, Juhlin C, Oberg K, Skogseid B, Langstrom B, et al. Whole-body (11)C5-hydroxytryptophan positron emission tomography as a universal imaging technique for neuroendocrine tumors: comparison with somatostatin receptor scintigraphy and computed tomography. J Clin Endocrinol Metab. 2005;90(6):3392-3400.

3. Yang J, Kan Y, Ge BH, Yuan L, Li C, Zhao W. Diagnos- tic role of Gallium-68 DOTATOC and Gallium-68 DOTATATE PET in patients with neuroendocrine tumors: a meta-analysis. Acta Radiol. 2014;55(4):389-398.

4. Ilias I, Torpy DJ, Pacak K, Mullen N, Wesley RA, Nieman LK. Cushing's syndrome due to ectopic corticotropin secretion: twenty years' experience at the National Institutes of Health. J Clin Endocrinol Metab. 2005;90(8):49554962.

5. Lin CJ, Perng WC, Chen CW, Lin CK, Su WL, Chian CF. Small cell lung cancer presenting as ectopic ACTH syndrome with hypothyroidism and hypogonadism. Onkologie. 2009;32(7):427-430.

6. Lionakis MS, Kontoyiannis DP. Glucocorticoids and invasive fungal infections. Lancet. 2003;362(9398):18281838.

7. Aucott JN. Glucocorticoids and infection. Endocrinol Metab Clin North Am. 1994;23(3):655-670.

8. Fareau GG, Vassilopoulou-Sellin R. Hypercortisolemia and infection. Infect Dis Clin North Am. 2007;21(3):639657, viii.

9. Rizwan A, Sarfaraz A, Jabbar A, Akhter J, Islam N. Case report: nocardia infection associated with ectopic cushings. BMC Endocr Disord. 2014;14:51.

10. Dohchin A, Sato M, Yamanaka H, Takahashi T, Suzuki J, Yamaguchi E, Kawakami Y. [Pulmonary nocardiosis associated with Cushing's syndrome]. Nihon Kokyuki Gakkai Zasshi. 1999;37(2):125-129.

11. Huang TP, Wang PW, Liu RT, Tung SC, Jean WY, Lu YC, Hung CL, et al. Ectopic ACTH syndrome with nocardiosis - a case report. Changgeng Yi Xue Za Zhi. 1994;17(4):371-377.

12. Sutton BJ, Parks GE, Manavi CK, Palavecino EL, Geisinger KR. Cushing's syndrome and nocardiosis associated with a pulmonary carcinoid tumor: report of a case and review of the literature. Diagn Cytopathol. 2011;39(5):359362.

13. Trainer PJ, Grossman A. The diagnosis and differential diagnosis of Cushing's syndrome. Clin Endocrinol (Oxf). 1991;34(4):317-330.

14. Invitti C, Pecori Giraldi F, de Martin M, Cavagnini F. Diagnosis and management of Cushing's syndrome: results of an Italian multicentre study. Study Group of the Italian Society of Endocrinology on the Pathophysiology of the Hypothalamic-Pituitary-Adrenal Axis. J Clin Endocrinol Metab. 1999;84(2):440-448.

15. Wajchenberg BL, Mendonca BB, Liberman B, Adelaide M, Pereira A, Kirschner MA. Ectopic adrenocorticotropin hormone syndrome. Endocr Rev. 1994;15(6):752-787.

16. Raffin-Sanson ML, Massias JF, Dumont C, Raux-Demay MC, Proeschel MF, Luton JP, Bertagna X. High plasma proopiomelanocortin in aggressive adrenocorticotropin-secreting tumors. J Clin Endocrinol Metab. 1996;81(12):4272-4277.

17. Newell-Price J, Trainer P, Besser M, Grossman A. The diagnosis and differential diagnosis of Cushing's syndrome and pseudo-Cushing's states. Endocr Rev. 1998;19(5):647-672.

18. Stewart PM, Walker BR, Holder G, O'Halloran D, Shackleton $\mathrm{CH} .11$ beta-Hydroxysteroid dehydrogenase activity 
in Cushing's syndrome: explaining the mineralocorticoid excess state of the ectopic adrenocorticotropin syndrome. J Clin Endocrinol Metab. 1995;80(12):3617-3620.

19. Biller BM, Grossman AB, Stewart PM, Melmed S,
Bertagna X, Bertherat J, Buchfelder M, et al. Treatment of adrenocorticotropin-dependent Cushing's syndrome: a consensus statement. J Clin Endocrinol Metab. 2008;93(7):2454-2462. 